\title{
Essay on the Theory of Disclosure
}

\author{
Bruno Meirelles Salotti \\ University of São Paulo \\ Marina Mitiyo Yamamoto \\ University of São Paulo
}

\begin{abstract}
The present essay is based on the paper by Verrecchia (2001) and seeks to present and discuss the analytical models developed from the theory of disclosure. Initially, research on this subject is classified into three categories: based on association, discretion and efficiency. Mathematical relations are shown for each category seeking to represent the disclosure phenomenon and the variables related to it. Besides this, game theory is presented as another possible approach to model the disclosure process. It is hoped that such models will serve as a theoretical base to develop hypotheses and conduct further research for empirical verification of these hypotheses, and consequently, based on such evidence, to improve the models to better represent the reality of the disclosure process.
\end{abstract}

Key words: Cost of capital, disclosure, corporate governance.

Received in 08/06/2005; revised in 14/06/2005; accept in 14/06/2005.

* Corresponding authors:

Bruno Meireles Salloti

Doutor em Controladoria e

Contabilidade

Universidade de São Paulo

Adress: Av. Prof. Luciano Gualberto,

908 - Prédo III, Cidade Universitária,

CEP: 05508900 - Sao Paulo - SP -

Brazil

Email: brasilbrunofea@usp.br

Telephone: (11) 30915820
Marina Mitiyo Yamamoto

Doutor em Controladoria e

Contabilidade

Universidade de São Paulo

Adress: Av. Prof. Luciano Gualberto,

908

52

Prédo III, Cidade Universitária, CEP

05508900 -

Sao Paulo-SP-Brazil

Email: brasilmarinamy@usp.br

Telephone: (11) 30915820 


\section{INTRODUCTION}

Starting particularly in the 1960s and 70s, accounting research at the international level underwent important transformations in the methodological sphere. Up to then, accounting research focused mainly on the normative side, i.e., a prescriptive approach, supplying theoretical solutions, dictating rules, in short, determining what must be adopted by accounting practice. The positive approach emerges in contrast to this type of research, suggesting building up a theory based on empirical evidence. With this, the theory attains the objective of "describing how accounting is actually practiced in the real world and forecasting what will occur (predictive power)" (DIAS FILHO and MACHADO, 2004, p. 15).

The positive methodology usually begins developing a determined subject starting with analytical articles, that is, works with descriptions of mathematical models seeking to develop relations among variables. Thereafter, these models furnish theoretical underpinnings to prepare hypotheses, which are tested with real-world data. Once tested, the models are adjusted or adapted to expand their ability to explain reality.

In Brazil the tendency to replace the normative approach with the positive one has also occurred, albeit more slowly than in international circles, and there are still quite a few new works appearing in the normative field. Despite this, Dias Filho and Machado (2004, p. 3031) point out that:

“...accounting research has been increasingly endeavoring to supply explanations and predictions for accounting practice. In light of this methodology, various questions have started to be examined with greater scientific rigor. For example, we can cite the relevance of accounting information to certain economic agents, the role of regulation, the role of accounting in reducing conflicts of interest, the reasons why one or another accounting method is being used, and other similar questions."

One subject that has been addressed since the 1980s by the international positive accounting literature is called the "theory of disclosure". Many papers have been written in the leading international journals (for example, see Verrecchia, 1983 and Dye, 1985). The main objective of this line of thought is to explain the phenomenon of disclosure of financial information from diverse perspectives, such as the effect of financial statement disclosure on stock prices, the economic reasons are for certain information to be revealed voluntarily, etc.

In 2001, the Journal of Accounting and Economics published a group of surveys addressing accounting research in overall terms, i.e., seeking to summarize the research already carried out on such subjects and to suggest future paths. Robert E. Verrecchia was tasked to write a survey of the state of the art in accounting research related to the theory of disclosure. Besides this, Ronald A. Dye was chosen to comment on Verrecchia's article. The result was "Essays on Disclosure" by Verrecchia and "An Evaluation of 'Essays on Disclosure' and the Disclosure Literature in Accounting" by Dye.

In view of the importance and ample international development of this field of study, and its minimal (even trifling) use in Brazil to explain phenomena related to disclosure of accounting information, the present article seeks to summarize the ideas of Verrecchia (2001), in this way furnishing theoretical support to develop this line of investigation in this country.

Verrecchia's article (2001) is presented according to an analytical approach, describing the mathematical models developed by the theory to explain and predicts disclosure-related phenomena.

Hence, this work, to the extent it aims to summarize the central ideas of Verrecchia (2001), also can be called analytical. In other words, its proposed contribution is to present 
such models so they can be employed in future studies to develop hypotheses that can be tested empirically.

\section{THEORY OF DISCLOSURE}

Verrecchia (2001, p. 98) begins his paper with arguments on the absence of a unified theory of disclosure:

"(...)there is no comprehensive, or unifying, theory of disclosure, or at least none that I felt comfortable identifying as such. In the disclosure literature, there is no central paradigm, no single compelling notion that gives rise to all subsequent research, no well-integrated 'theory'..."

Faced with such difficulty, he points out that his work is more modest, since it takes a small and preliminary step in search of a comprehensive theory.

Verrecchia (2001, p. 99) describes the purpose of his work as to classify the various models that deal with the subject, proposing a taxonomy encompassing three broad categories of work on accounting disclosure:

- Association-based disclosure;

- Discretionary-based disclosure;

- Efficiency-based disclosure.

The first of these categories includes studies whose main goal is to investigate the relation or association between disclosure (as an exogenous process) and changes in the behavior of investors, who compete in the capital market to maximize their welfare (or wealth). The main characteristic of this type of work is to study the effects of disclosure on investors' actions, principally through the price behavior of assets in equilibrium and the volume of trading.

The second category takes in works that identify the motives for disclosure, that is, it seeks to examine how managers and/or firms disclose certain information. In this form, disclosure is an endogenous process, considering the incentives that managers and/or firms have to disclose information. In this case, the capital market is considered the only representative consumer of information disclosed by companies.

The third category covers works about which disclosure configurations are preferred, in the absence of past knowledge of the information - in other words, no disclosure has occurred yet - so it can be characterized as being ex ante. Works classified in this category discuss which are the most efficient types of disclosure, i.e., those unconditionally preferred. In this case, the actions of capital market agents that maximize welfare are endogenous.

Below is a table summarizing the main characteristics that set the three categories apart. 
TABLE 1

Characteristics of Disclosure Study Categories

\begin{tabular}{c|c|c}
\hline \multirow{2}{*}{ Category } & \multicolumn{2}{|c}{ Disclosure Characteristics } \\
\cline { 2 - 3 } & $\begin{array}{c}\text { Moment of Disclosure } \\
(\text { ex ante or } \text { ex post })\end{array}$ & $\begin{array}{c}\text { Disclosure Process } \\
\text { (endogenous or exogenous })\end{array}$ \\
\hline Association & ex post & Exogenous \\
\hline Discretionary & expost & Endogenous \\
\hline Efficiency & ex ante & Not applicable \\
\hline
\end{tabular}

Source: Prepared by the authors.

The table above shows that in relation to the first disclosure characteristic, the "efficiency" category stands out from the other two because it is treated as ex ante, analyzing what type of disclosure is preferable before its occurrence. So, the objective is to attain maximum efficiency by disclosing preferable information.

Assuming that the disclosure has already occurred, i.e., ex post, the disclosure process can be divided into the "association" and "discretionary" categories. In the former, the company's motives are not at issue, meaning the disclosure process is exogenous. In the latter, these motives are considered (hence endogenous), and so the question is focused on why the firm reveals certain information or not.

The following sections present the models developed for each category of accounting disclosure research. Then game theory is introduced as an alternative approach to model the disclosure process. Finally, some closing considerations are set out, along with suggestions for future studies.

\section{WORKS ON ASSOCIATION-BASED DISCLOSURE}

The ideas presented below were developed by Verrecchia (2001, pp. 101-140) ${ }^{\mathrm{i}}$. As mentioned before, the works on association-based disclosure seek to examine the relationship between the disclosure phenomenon and changes in the behavior of diversified and competing investors to maximize their welfare. This examination is carried out by characterizing the effects of disclosure on the cumulative actions of individual investors at the moment the disclosure takes place. A particularly interesting example of this type of study is verified between the disclosure and change in share prices.

Below is a simple model, developed in the literature to represent the relation between the disclosure and price change.

To start the development of a disclosure model, assume the existence of some asset (in general, a firm), whose value is uncertain and about which some information is disclosed. The uncertainty can be represented by a random variable of any variability, although the normal distribution is mathematically more acceptable and understood at an intuitive level by the majority of authors. Consequently, it is assumed that the uncertain value of the firm is represented by the variable $\tilde{u}$, which is normally distributed with mean $m$ and precision (the inverse of the variance) $h$. This precision can be interpreted as the prevailing level of common knowledge in the market about the uncertain value of the firm, $\tilde{u}$. Now, if the variance of $\tilde{u}$ is large (meaning the firm's uncertain value is highly variable about the mean), then the precision $h$ of the mean $m$ is low (the inverse of a large number is a small one). Hence, the market has little knowledge about the firm's worth, and for this reason the variance is high. 
Similarly, assume that some information is disclosed about the firm's value, but that information is not perfect. In this form, the disclosure $\tilde{y}$ can be represented by the following formula: $\tilde{y}=\tilde{u}+\tilde{\eta}$, where $\tilde{\eta}$ also is normally distributed with mean 0 and precision $n$. This precision can be interpreted as the informative content of the disclosure, $\tilde{y}$, i.e., if $\tilde{y}$ supplies quality information about the value $\tilde{u}$, then the value $\tilde{\eta}$ tends to zero, and hence the variance of $\tilde{\eta}$ is low, implying that the precision $n$ is high The high precision indicates that the information revealed about the firm is appropriate.

Finally, two economic periods are assumed: time $T-1$ is the moment immediately before the disclosure and time $T$ is that just afterward (i.e., the disclosure period). The asset's prices at moments $T-1$ and $T$ are represented by $P_{T-1}$ and $P_{T}$, respectively. Finally this analysis is ceteris paribus, meaning that all other elements other than those studied are fixed or constant.

To evaluate the price changes, suppose that such changes occurring at moment $T$ have the following functional form:

$$
\widetilde{P}_{T}-\widetilde{P}_{T-1}=\alpha+\beta(\tilde{y}-m)+\gamma \widetilde{\Omega}+\tilde{\xi},
$$

where $\alpha, \beta$ and $\gamma$ are fixed parameters, $\widetilde{\Omega}$ represents other variables besides $\tilde{y}$ related to the firm's worth and the price changes, and $\tilde{\xi}$ represents variables unrelated to the firm's value (in general, noise). The coefficient $\beta$ can be interpreted as the element of the price-change relation resulting directly from the disclosure, i.e., the disclosure response coefficient (DRC) in the price change. This coefficient shows how much the price change depends on the disclosure.

Besides the relation between the change in price and disclosure, one can also calculate the percentage of variability of the price change at moment $T$ explained exclusively by the disclosure. To do this, it is necessary to control for other factors, such as $\widetilde{P}_{T-1}$ and $\tilde{\xi}$. The price at $T-1$ has to be controlled by eliminating from the variability of price change the part of the variability that results from activities before the disclosure, as captured by $\widetilde{P}_{T-1}$. The noise, in turn, is controlled, since its contribution to the variation in price change is not economically relevant. After controlling for these factors, the percentage of variability of the price change explained exclusively by the disclosure at moment $T$ (statistic $\Delta \%$ ) can be described according to:

$$
\Delta \%=1-\frac{\operatorname{VAR}\left[\tilde{P}_{T}-\tilde{P}_{T-1} \mid \tilde{y}=y, \tilde{P}_{T-1}=P_{T-1}, \tilde{\xi}=\xi\right]}{\operatorname{VAR}\left[\tilde{P}_{T}-\tilde{P}_{T-1} \mid \tilde{P}_{T-1}=P_{T-1}, \tilde{\xi}=\xi\right]}
$$

In these association-based disclosure models, the assumption is that all investors in the market are risk neutral, can assume unlimited liability for realizations of firm value, and have no information (private or public) about firm value at time $T-1$. Due to the absence of information at time $T-1$, all expectations are based on the unconditional expectation of $\tilde{u}$, which is $m$. Besides this, since the investors are risk neutral, the share price at time $T-1$ is equal to a $m$. At time $T$, the disclosure occurs (i.e., $\tilde{y}=y$ is revealed). It is assumed that this is the only information on the firm's value, if there is other information about firm value disclosed at the same time (normally, private information), it is subsumed in $\tilde{y}=y$. In other words, to value the firm, $\tilde{y}$ is a sufficient statistic for $\tilde{y}$ and all other information. Hence:

$$
P_{T}=E[\tilde{u} \mid \tilde{y}=y]=m+\left[\frac{n}{h+n}\right](y-m) .
$$


This implies that $\tilde{P}_{T}-\tilde{P}_{T-1}=\left[\frac{n}{h+n}\right](\tilde{y}-m)$.

The expression $(\tilde{y}-m)$ can be interpreted as the "disclosure surprise factor", because it represents the extent to which $\tilde{y}=y$ deviates from the expected value of $m$, which is also the expected value of $\tilde{u}$. In this case, the coefficient of the response to the disclosure is the factor $n$ $/(h+n)$, which can be described as the precision of disclosure $n$ relative to the total precision of the firm's value conditional on the disclosure, $h+m$. In other words, the DRC is the information content of the disclosure relative to all that is known about the firm's value after the disclosure.

Finally, note that in this simple model all the variability in price change is explained by the disclosure at time $T$. For example, $\operatorname{VAR}\left[\tilde{P}_{T}-\tilde{P}_{T-1} \mid \tilde{y}=y\right]=0$. Therefore, the $\Delta \%$ statistic of this model is equal to 1 .

The characterization of the model presented can be considered transparent but superficial. Nevertheless, the model's elegance is achieved at the expense of an extreme stylization of how markets function. For example, in this model, there is no information on the firm's value with relevance beyond that resulting directly from the disclosure. Besides this, the model describes a world in which no trades occur. This can be explained by the homogenous opinions in both periods, $T$ and $T-1$, and hence there is no rational reason for the existence of trading based on information.

Therefore, a minimum condition to make the model more robust is the existence of some volume of trading at the time of the disclosure. To relate the volume of transactions to the disclosure, it is probable it will be necessary to resort to some elements of the investor's diversity: for example, differences of opinion, abilities, ways of using information, etc.

The development of this simple model from including other variables and modifying some premises permits the elaboration of other models, as cited below ${ }^{\text {ii }}$

- Investors are informed differently;

- Investors make rational inferences from market prices;

- Investors anticipate the disclosure rationally;

- Investors, besides being informed differently, also have information of diverse quality, or heterogeneous information;

- Investors interpret the disclosure in different ways;

- Investors incorporate the disclosure in their opinions in diverse fashion, i.e., only some agents incorporate the disclosure in their subsequent expectations;

- Investors condition their opinions according to different economic stimuli, i.e., they make rational inferences from both market prices and trading volume.

Put succinctly, works on association-based disclosure have been successful because they offer detailed descriptions of the relations or associations between disclosure, price changes, trading volume or some other market phenomenon. The models can be considered robust, easy to work with and deal with a variety of interesting descriptions. Nevertheless, a critical premise held in these models is that the disclosure process is exogenous. Studies on disclosure that alter this premise (because they treat disclosure endogenously) are included in the second category, discussed below.

\section{WORKS ON DISCRETIONARY-BASED DISCLOSURE}


When the disclosure process is treated as endogenous, researchers question the motives about whether or not to disclose certain information. In other words, they assume that management can choose between revealing and not revealing some given information. In this form, these works ask under what conditions disclosure will or will not occur.

To answer these and other questions, works have been developing what is called the theory of voluntary disclosure. On this aspect, Dye (2001, p. 184) disagrees with Verrecchia (2001) when the latter mentions there is no disclosure theory. For Dye (2001, p. 184):

"There is a theory of voluntary disclosures. The theory of voluntary disclosures is a special case of game theory with the following central premise: any entity contemplating making a disclosure will disclosure information that is favorable to the entity, and will not disclose information unfavorable to the entity. theory:

Dye (2001, pp. 184-185) also demonstrates some examples of applications of this

"Consider a car salesman who extols the reliability of a car, but dos not mention its performance. The theory permits us to conclude that the car's performance is not very good. Consider someone whose resume looks extraordinary, except for an unaccounted 15-year gap following graduation from college. The theory permits us to infer either that the person was in prison, in graduate school, or engaged in some other nefarious activity during this extended time interval. Consider a firm that in the "highlights" section of its annual report, repeatedly stresses its success in achieving cost reductions but does not mention revenues. The theory permits us to infer that the firm's revenue growth was disappointing, even before inspecting the firm's income statement."

Apart from the discussion on the existence or not of the theory of disclosure, the contributions of Verrecchia (2001, pp. 141-160) are summarized below ${ }^{\mathrm{iii}}$.

A very important concept to supply theoretical backing for this type of research is the problem of adverse selection. The logic of this concept can be perceived when a rational buyer interprets withheld information as unfavorable information about the asset's value or quality. Consequently, the buyer discounts the asset's value until the point where it is in the firm's best interests to reveal the information, no matter how unfavorable it may be. The notion that withheld information can be revealed because of the behavior of rational buyers is a seminal result that forms the basis for nearly all later research on this topic.

Extending this idea into the realm financial reporting, it can be seen that when a considerable amount of financial disclosure is compulsory (e.g., quarterly reporting, annual reports, balance sheets, income statements, etc.), managers may have additional information whose disclosure is not required, but is nevertheless useful to value the firm's future perspectives. Therefore, the question arises as to what circumstances will cause managers to disclose or withhold this information.

In the accounting literature, various works on this subject ${ }^{\mathrm{iv}}$ suggest the following: if a manager's goal is to maximize the firm's current market capitalization and there are costs associated with disclosing information, there is an equilibrium, with the information that reflects favorably on the current market value being disclosed and that which reflects unfavorably being withheld. In this case, the market agents (generally investors) have rational expectations that the content of the undisclosed information is unfavorable. 
Regarding the variety of costs that can support withholding information, an edifying example is the cost associated with disclosing information that is by nature proprietary. For example, if a certain company's productive process is revealed in detail, this can bring other competitors, causing the company to lose market share.

Three aspects deserve mention regarding the accounting literature on this theme: (1) the dependence on private $\operatorname{costs}^{\mathrm{v}}$ to explain withholding information; (2) the reliance on reporting correct and honest information; and (3) the dependence on the manager's aim as one of the stimuli to the firm's current capitalization, even in the event this practice jeopardizes the future value of the firm.

In relation to the first aspect, according to the literature, uncertainty offers an alternative rationale for not disclosing information in the absence of exogenous costs related to the production of proprietary information. For example, the possibility exits that such information is withheld because there is uncertainty about whether the manager has the information, or equivalently, that the information in question is ready yet. The existence of uncertain or recently produced information operates as a type of disclosure cost because it creates doubts in uninformed investors' minds, and thus ameliorates the adverse selection problem. This argument supports withholding information.

Besides this, there is also the possibility that information will not be disclosed because of the uncertainty over the types of managers or companies involved. In the first case, information may be rationally withheld because it can be used to value the human capital of the manager or of the firm. In the second case, information may be withheld because the benefit (or cost) of a favorable (or unfavorable) report has to be weighed against the gain (or loss) of credibility at a subsequent date when more information is forthcoming.

Regarding the second premise, questions have been raised about the assumption that if management decides to disclose its private information, then it does this truthfully. Truthful disclosure is typically justified by the possibility of some cost of litigation and eroded human capital associated with the dissembling. While this restriction appears to describe many situations in accounting where audited financial statements may corroborate management's disclosure, there are situations, such as provision of future information (contingency provisions, for example) where it is more difficult to judge management's integrity.

The third aspect causes the most disagreement in the accounting literature. To illustrate this question, the following example is presented: if there are costs associated with reporting certain information whose dissemination is not required, and the only effect of disclosing it is to improve immediately, but only temporarily, the firm's current market price, perhaps the firm's shareholders should ask management never to disclose this information. In other words, the question posed is to what point does maximizing the firm's current capitalization lead to destroying its future value.

Some reasons are pointed to in the literature for management to be concerned more with the firm's current than future value, such as the existence of doubt as to whether certain managers will still be working at the firm to be rewarded for the firm's future value. There are other reasons as well related to the manager's behavior, such as the fact that managers can be conditioned to believe they are being evaluated by the company's current value. To confirm this argument, one can refer to various articles on upper-level managers, normally relating their tenure with the firm to an increase or decrease in the firm's market worth.

Below we present a model that tries to assess how the existence of fixed costs related to private information or uncertainty over the existence of withheld information leads to an equilibrium, with the information then either being disclosed or not, assuming that the firm seeks to maximize its current value. 
Consider a firm producing a determined good in a certain period, based on the product's demand in the next period. This demand is characterized by a price $P$, which can be represented by:

$$
P=\alpha+\beta \tilde{Y}-x
$$

where $\alpha$ and $\beta$ are fixed positive constants $(\alpha>0$ and $\beta>0), \tilde{Y}$ refers to some private information on the price in the next period, known only to the firm, and $x$ represents the quantity of the good produced by the firm in this period. In other words, the company produces $x$ in this period to obtain revenue of $x . P$ in the next period. Because the realizations of $\tilde{Y}$ are private, such information is known to the market only if the firm discloses it.

If the information is withheld, the market treats $\tilde{Y}$ as an unknown random variable, distributed uniformly between $-k$ and $k$. In this case, a positive association is assumed between the realizations of $\tilde{Y}=Y$ in the interval between $-k$ and $k$ and the firm's revenue for the next period, $x . P$. As a result of this positive association, progressively greater realizations of $\tilde{Y}=Y$ can be interpreted as "good news", because it indicates higher revenue in the next period. As shown below, a necessary condition to attain a positive association is to assume that $\alpha \geq \beta k$. Besides this, it is assumed that the company's discretionary disclosure policy is to maximize its present value. Because progressively greater realizations of $\tilde{Y}=Y$ imply "good news", the company is predisposed to disclose greater realizations of $\tilde{Y}=Y$ as an indication of increased revenue in the next period.

Since $\tilde{Y}=Y$ is private knowledge, the firm faces a dilemma, since this information can be used by competitors to produce the same products or others as substitutes.

Assume also that the private costs ${ }^{\mathrm{vi}}$ associated with disclosing any realization of $\tilde{Y}=Y$ are represented by $c$, where $c>0$. This implies that these costs are fixed and do not vary, irrespective of the information.

To determine whether the company discloses its proprietary information, consider its investment decision when $\tilde{Y}=Y$ is revealed. In this situation, the firm produces the quantity $x$ to maximize:

$$
\max x \cdot E[\tilde{P} \mid \tilde{Y}=Y]=x(\alpha+\beta Y-x) \text {. }
$$

The above function can be rewritten as $f(x)=-x^{2}+(\alpha+\beta Y) x$ and thus is concave on $x$. The maximum value taken on by $x$ in this function can be determined by the formula for the vertex of a parabola, since it is in the form $a x^{2}+b x+c$ :

$$
\begin{aligned}
& x_{v}=-\frac{b}{2 a}, \text { where } a=-1 \text { and } b=(\alpha+\beta Y) . \text { Hence, } \\
& x_{v}=-\frac{\alpha+\beta Y}{2 .(-1)}=\frac{1}{2}(\alpha+\beta Y)^{\mathrm{vii}} .
\end{aligned}
$$

So, the quantity that maximizes $f(x)$ is $1 / 2(\alpha+\beta Y)$. The sale price of this quantity in the next period is:

$$
P=\alpha+\beta Y-x=\alpha+\beta Y-\left[\frac{1}{2}(\alpha+\beta Y)\right]=\frac{1}{2}(\alpha+\beta Y) .
$$

Assuming $\alpha \geq \beta k$ implies that the amount produced in this period and the price at which the good is sold next period, i.e., $x=P=1 / 2(\alpha+\beta Y)$, are both nonnegative for any $Y \in[-$ $k, k]$. Additionally, regardless of whether or not the firm discloses $\tilde{Y}=Y$, its revenue the next period (exclusive of any private costs) is $x . P$. Substituting $x$ and $P$ (from the above formula), the revenue equals:

$$
x . P=\left[\frac{1}{2}(\alpha+\beta Y)\right] \cdot\left[\frac{1}{2}(\alpha+\beta Y)\right]=\frac{1}{4}(\alpha+\beta Y)^{2} .
$$


Finally, note that for any $Y \in[-k, k]$, the derivative of $x . P$ with respect to $Y,(\mathrm{~d} / \mathrm{d} Y) x . P=$ $1 / 2 \beta(\alpha+\beta Y) \geq 0$ when $\alpha \geq \beta k$. Because of this, the realizations of $\tilde{Y}$ and the revenue are positively associated.

The market values the firm based on its knowledge of the revenue in the next period (if $\tilde{Y}=Y$ is disclosed) or on its expectation of revenue (if $\tilde{Y}=Y$ is withheld). When $\tilde{Y}=Y$ is disclosed, the market recognizes that the revenue next period, including the private cost, is:

$$
E[\tilde{x} . \tilde{P} \mid \tilde{Y}=Y]=\frac{1}{4}(\alpha+\beta Y)^{2}-c .
$$

Alternatively, when $\tilde{Y}=Y$ is not disclosed, because realizations of $\tilde{Y}=Y$ and revenue are positively associated, the market envisions that the realizations of $\tilde{Y}$ that are withheld must be below some cut-off point or threshold $\hat{Y}$ that does not warrant incurring the private cost $c$. Therefore, when $\tilde{Y}=Y$ is not disclosed, the market assesses the firm's revenue in the next period as:

$$
\begin{aligned}
& E[\tilde{x} . \tilde{P} \mid \tilde{Y}=Y \leq \hat{Y}]=E\left[\frac{1}{4}(\alpha+\beta \tilde{Y})^{2} \mid \tilde{Y}=Y \leq \hat{Y}\right]= \\
& =\frac{1}{12}\left[3 \alpha^{2}+3 \alpha \beta(\hat{Y}-k)+\beta^{2}\left(\hat{Y}^{2}-\hat{Y} k+k^{2}\right)\right]
\end{aligned}
$$

According to this, based on the realization of $\tilde{Y}=Y$, the difference between disclosing or withholding this information on the firm's current market value is:

$$
\begin{aligned}
& E[\tilde{x} . \tilde{P} \mid \tilde{Y}=Y]-c-E[\tilde{x} . \tilde{P} \mid \tilde{Y} \leq Y]= \\
& =\frac{1}{4}(\alpha+\beta Y)^{2}-c-\frac{1}{12}\left[3 \alpha^{2}+3 \alpha \beta(\hat{Y}-k)+\beta^{2}\left(\hat{Y}^{2}-\hat{Y} k+k^{2}\right)\right]
\end{aligned}
$$

Consequently, the firm is motivated to disclose $\tilde{Y}=Y$ when this expression is positive and not to do so when it is negative. This behavior maximizes the market's expectation of the firm's revenue in the next period, and thus the firm's current value.

The value of $\tilde{Y}$ that makes the firm indifferent between disclosing and withholding the information is the threshold level of disclosure $\hat{Y}$. In this form, when $Y \geq \hat{Y}$, the expression $E[\tilde{x} . \tilde{P} \mid \tilde{Y}=Y]-c-E[\tilde{x} . \tilde{P} \mid \tilde{Y} \leq Y]$ is nonnegative, and when $Y<\hat{Y}$ it is negative.

It can be shown that there is a unique threshold level of disclosure when:

$$
\hat{Y}=-\frac{1}{4 \beta}\left(3 \alpha+\beta k-\sqrt{9(\alpha-\beta k)^{2}+96 c}\right) \text {. }
$$

This threshold has the feature that $\hat{Y}>-k$, as long as $c>0$.

This threshold can be interpreted economically as the level of information that leaves the firm indifferent between divulging $\tilde{Y}=Y$ at a cost $c$ and not disclosing the realization $\tilde{Y}=Y$. Because values of $\tilde{Y}=Y$ greater than $\hat{Y}$ indicate high demand for the product, the firm wants to provide this information to the market for valuation purposes in spite of the private costs associated with this decision. Alternatively, since values of $\tilde{Y}=Y$ below $\hat{Y}$ indicate average or low demand for the product, the company is convinced to withhold knowledge of $\tilde{Y}=Y$ because this information does not improve its valuation, and entails private costs as well. Note that when $c=0, \hat{Y}=-k$. In other words, in the absence of private costs, the only threshold in equilibrium is one that implies full disclosure. And as $c$ increases, $\hat{Y}$ diminishes. In other words, the disclosure threshold increases as costs increase.

Most of the literature on this subject has concentrated mainly on the disclosure thresholds, but the focus should be on the unconditional probability of disclosure, since from 
an empirical standpoint, these thresholds cannot be observed. The probability of disclosure, in turn, potentially can be known, by means of repeated observations of a discretionary disclosure. In this form, if $\hat{Y}$ is a random variable uniformly distributed between $k$ and $-k$, then the probability of disclosure is:

$$
\begin{aligned}
& \max \left[\frac{1}{2 k} \int_{\hat{Y}}^{k} \mathrm{~d} Y, 0\right]=\max \left[\frac{1}{2 k}(k-\hat{Y}), 0\right]= \\
& =\max \left[\frac{1}{8 \beta \cdot k}\left(5 \beta \cdot k+3 \alpha-\sqrt{9(\alpha-\beta \cdot k)^{2}+96 c}\right), 0\right] .
\end{aligned}
$$

Note that the disclosure probability is less than 1 provided that $c>0$, and greater than zero provided that $c$ is not very high.

Now consider the relation between disclosure and information quality. Note that managers are assumed to know the information quality (i.e., they know $Y$ ), while à priori the market only knows that $\tilde{Y}$ is uniformly distributed between $k$ and $-k$. The variance of a uniformly distributed random variable is $1 / 3 k^{2}$, i.e., the variance increases as $k$ increases.

Consequently, $k$ can be interpreted as a measure of information asymmetry, or the ex ante difference in the quality of the information known to management and market. The higher $k$ is, the less the market knows relative to management à priori. In this context, an interesting question is how the disclosure threshold level changes as information asymmetry between the market and management grows. According to the model here, the likelihood of disclosure generally rises as $k$ rises. This implies that as information asymmetry between the market and management grows, in equilibrium management is more prone to disclose. This result is eminently reasonable: a greater disparity between management's knowledge and the market's exacerbates the adverse selection problem. Hence, mitigating this problem requires more disclosure.

The alteration of some premises of this model, such as assuming the private costs may not be constant, stimulates the development of three other models. For more details on these, consult Verrecchia (2001, pp. 152-160).

From this analytic model, one can draw the following conclusion: under the hypothesis of the existence of costs and/or uncertainty, managers decide to disclose or withhold certain information on the value of the firm despite the fact market agents interpret this lack of information rationally. In other words, the literature contains an interesting economic story about the incentives on management or the firm to disclose information voluntarily. However, disclosure strategies based on discretion along are typically inefficient, because for the firm the prior commitment never to disclose is the best strategy. In this fashion, research has come to address disclosure from a perspective of efficiency.

\section{WORKS ON EFFICIENCY-BASED DISCLOSURE \\ $\mathrm{V}$.}

The studies in this category seek to shed light on the existence of some forms of disclosure that promote efficiency, that is, those preferred unconditionally. According to Verrecchia (2001, p. 160):

"Notions of efficiency are central to economics. Therefore, if one objective of the disclosure literature is to forge a link between financial reporting and economics, failure to integrate efficiency into the discussion may be a fatal oversight."

Regarding this category of research, Dye (2001, p. 224) comments: 
"Consider a car salesman who extols the reliability of a car, but dos not mention its performance. The theory permits us to conclude that the car's performance is not very good. Consider someone whose resume looks extraordinary, except for an unaccounted 15-year gap following graduation from college. The theory permits us to infer either that the person was in prison, in graduate school, or engaged in some other nefarious activity during this extended time interval. Consider a firm that in the "highlights" section of its annual report, repeatedly stresses its success in achieving cost reductions but does not mention revenues. The theory permits us to infer that the firm's revenue growth was disappointing, even before inspecting the firm's income statement."

The existing models in this category are summarized below, based on the paper by Verrecchia (2001, pp. 160-172) viii $^{\text {. }}$

In primary capital markets, a firm's shares are sold to investors to raise cash needed for investment. One type of cost related to disclosure that inhibits investment and thus makes it more costly for the firm to sell shares is the transaction cost arising from the adverse selection problem inherent in the exchange of assets among investors with various levels of information knowledge. This transaction cost is called "the information asymmetry component of the cost of capital". This component is the discount that firms offer as a way of accommodating the adverse selection problem. Therefore, in search of efficiency, the firm tries to decrease the information asymmetry as a way to reduce the component of the cost of capital relative to this. A way to reduce asymmetry is for the firm to commit to a higher level of public disclosure at the time it offers its shares. Specifically, the company can pledge to prepare its financial statements using the most transparent accounting standards and procedures possible.

However, if the company benefits from having a good disclosure policy, and in this way reduces its cost of capital, then there will be doubt about the reason for the existence of a cost component relative to information asymmetry. In other words: What would keep the firm from choosing the solution of complete disclosure, eliminating with this any type of potential cost? Presumably, managers and/or companies do not choose the full disclosure solution, because there are costs related to revealing proprietary information, making this choice unfeasible. In this way, the model described below illustrates the concept of the cost of capital relative to information asymmetry and shows how the existence of private costs can lead to a policy in which disclosure is made in some cases and not in others.

Consider an entrepreneur who produces a certain good to sell in a market where there is one competitor. To begin the manufacturing process, in the first period the entrepreneur needs to raise $C$ monetary units of capital. To obtain this capital, the entrepreneur offers to sell a percentage $Q$ of the company to a risk-neutral investor, seeking to maximize his return from owning part of the company's revenue-generating activities, after selling $Q$ percent to the investor in exchange for $C$ units of money. The portion of these activities sold can be interpreted as the entrepreneur's cost of capital.

Each company invests in an initial period to produce goods, anticipating that these products will be sold for a price $P$ in a future period (i.e., a second period). $P$ can be represented by

$$
P=\alpha+\beta \tilde{Y}-x_{e}-x_{o}
$$

where $\alpha$ and $\beta$ are fixed positive constants, $\tilde{Y}$ refers to some private information about the anticipated price, known only to the entrepreneur, and $x_{e}$ and $x_{o}$ are the amounts produced by 
the entrepreneur's company and the competitor, respectively. Each firm makes a decision on how much to produce without knowing the amount produced by the other. $\tilde{Y}$ is considered a random variable, uniformly distributed between $-k$ and $k$.

The investor's decision to invest with the entrepreneur is affected by the fact the investor anticipates, with probability $t$, a market signal to buy or sell a share of the company. After the $C$ monetary units of initial capital are obtained, the subsequent buying and selling of the firm's shares are carried out in the secondary market, whose participants can be divided into two groups of the same size: informed traders, who also know $\tilde{Y}=Y$, and uninformed traders, or liquidity traders, who do not know $\tilde{Y}=Y$ unless this information is revealed by the entrepreneur. In all cases, the trading is restricted to the buying or selling of one share of the company.

The trading of the firm's shares in the secondary market is executed by a large number of market makers and each of them has a responsibility to execute one demand order (to buy or sell one share) in the second period. The market makers also do not know $\tilde{Y}=Y$ unless it is divulged. In this way, one can assume there is a probability of $1 / 2$ that the market operator will execute an informed trader's demand order, and $1 / 2$ that of executing an uninformed trader's demand order. Therefore, market makers charge a fee to ensure they break even in carrying out trades. This fee can be interpreted as a "liquidity premium", charged for the trades executed with the presence of adverse selection.

To reduce the liquidity premium and make investing in the firm potentially more attractive in the initial period, the entrepreneur promises to disclose $\tilde{Y}=Y$ in the second period if $\tilde{Y}=Y \in[-q, q]$ and not to do so if $\tilde{Y}=Y \in[-k,-q] \cup[q, k]$. Intuitively, the entrepreneur's commitment can be interpreted as a decision to disclose anticipated news (i.e., $-q \leq Y \leq q$ ) but to withhold dramatic news (i.e., realizations of $\tilde{Y}$ in the tails of the distribution). Consequently, the higher (lower) the value of $q$ is (recalling that $0 \leq q \leq k$ ), the more (less) the entrepreneur pledges to disclose.

If $\tilde{Y}=Y$ is not revealed, the informed trader expects to gain the following amount, in function of the choice $q$ of the entrepreneur's disclosure ${ }^{\text {ix }}$ :

$$
\begin{aligned}
& \lambda(q)=\frac{1}{2(k-q)} \int_{-k}^{-q} \mid \frac{1}{9}\left(\alpha+\frac{3}{2} \beta Y\right)^{2}-\frac{1}{9}\left(\alpha^{2}+\frac{3}{4} \beta^{2} q^{2}+\frac{3}{4} q \beta^{2} k+\frac{3}{4} \beta^{2} k^{2}\right) \mathrm{d} Y+ \\
& +\frac{1}{2(k-q)} \int_{q}^{k} \frac{1}{9}\left(\alpha+\frac{3}{2} \beta Y\right)^{2}-\frac{1}{9}\left(\alpha^{2}+\frac{3}{4} \beta^{2} q^{2}+\frac{3}{4} q \beta^{2} k+\frac{3}{4} \beta^{2} k^{2}\right) \mathrm{d} Y .
\end{aligned}
$$

This means that if there is no disclosure, the market makers should charge each trader (or equivalently, each transaction) a liquidity premium of $1 / 2 \lambda(q)$ so as to break even in a market with a 50/50 mix of informed and uninformed traders.

The investor contributes $C$ monetary units of capital and expects to receive in return a percentage $Q(q)$ of the entrepreneur's expected revenue, given by $R(q)$. Additionally, the investor has probability $t$ of receiving a market signal (a "liquidity shock") to buy or sell more of the firm's shares. Even with this signal, the investor buys or sells these shares at their expected value. In this way, the only effect of such a liquidity shock on the investor's expected return is that in addition he must pay the liquidity premium of $1 / 2 \lambda(q)$. Assuming that competition to invest in the firm is perfect, then investors can only hope to break even when investing $C$ units of capital. Hence, this implies that the expected payout of investing with the entrepreneur is:

$$
Q(q) R(q)-C-\frac{k-q}{k} t \frac{1}{2} \lambda(q),
$$


where $[(k-q) / k]$ represents the probability the investor will receive a market signal during a period when the entrepreneur makes no disclosure. Therefore, to break even, the investor must receive a percentage $Q(q)$, where $Q(q)$ is determined by:

$$
Q(q)=\frac{C+[(k-q) / 2 k] t \lambda(q)}{R(q)} .
$$

This being the case, the entrepreneur receives the residual $1-Q(q)$. This analysis has a key aspect: potential investors rationally anticipate all the benefits and costs of investing before buying the firm's shares.

The question then arises of what type of disclosure policy will minimize the cost of capital to the entrepreneur. To answer this question, define the entrepreneur's return for selling $Q(q)$ percent of the company to the investor in return for $C$ units of capital as:

$$
(1-Q(q)) R(q)=\left(1-\frac{C+[(k-q) / 2 k] \cdot t \lambda(q)}{R(q)}\right) R(q)=R(q)-C-\frac{k-q}{2 k} t \lambda(q) \text {. }
$$

This results from the fact that investors seek to break even. Consequently, the type of disclosure policy that minimizes the entrepreneur's cost of capital is that which maximizes $R(q)-C-[(k-q) / 2 k] . t \lambda(q)$. This is a direct exercise to show that when the investor is immune to market signals (i.e., $t=0$ ), a policy of no disclosure maximizes $R(q)-C-[(k-q) / 2 k] . t \lambda(q)$ (i.e., $q=0)$.

To summarize this section, the cost of capital is the percentage of the firm the entrepreneur needs to sell to raise a fixed amount of capital. The information asymmetry component of the cost of capital is the difference of the cost of capital in the presence versus absence of an adverse selection problem arising from asymmetrical information. This is a consequence of the entrepreneur's inability to commit to a complete disclosure policy because of the existence of other disclosure costs (in general, private costs). An secondary purpose of this model is to show how liquidity premiums combined with proprietary costs can lead to efficient disclosure choices in which the company neither totally discloses nor totally withholds information. Normally, the entrepreneur commits to disclose some information to ameliorate problems arising from illiquid markets. However, the entrepreneur does not commit to full disclosure, because the private costs of this are very high.

\section{ANOTHER APPROACH: THEORY OF GAMES}

Besides the modeling seen to this point to describe the disclosure process, it is also possible to use another approach, known as game theory.

According to Mas-Colell, Whinston and Green (1995, p.219),

"A game is a formal representation of a situation in which a number of individuals interact in a setting of strategic interdependence. By that, we mean that each individual's welfare depends not only on her own actions but also on the actions of the other individuals. Moreover, the actions that are best for her to take may depend on what she expects the other players to do."

A game is characterized by a set of rules that define the players, their possible actions and the set of information available to each player. According to the rules, there is one possible set of results (also known as payoffs) and the players make their decisions rationally and with the objective of maximizing their payoffs.

According to Gremaud and Braga (1998, p.250), a game can be differentiated in relation to the number of players (one, two or $n$ players), the possible types of actions 
(cooperative or non-cooperative), the information available (complete or incomplete) and the results (constant-sum or variable-sum games). Besides this, there is differentiation as to the moment each player executes an action. If the players carry out their actions at the same time, the games are called simultaneous. If they take their actions one after the other, the games are called dynamic or sequential.

The games can be solved in various ways. In general, the solutions can be determined based on three strategic principles: dominant, based on the Nash equilibrium, and based on the "maximin" strategy

According to Pindyck and Rubinfeld (2002, pp.464-465), a dominant strategy is one "that is optimal regardless of what the opponent can do." According to these authors, when there is a dominant strategy for each player, the result of the game is called equilibrium of dominant strategies. These games can be analyzed objectively, because each player's optimal strategy is determined without worrying about those of the others.

The solution based on Nash equilibrium is also known as the no-regret solution, as explained by Gremaud and Braga (1998, p.255): "the combination of strategies employed leads to an outcome in which none of the players individually regret their actions, i.e., no player could have improved his situation unilaterally by modifying the chosen strategy." In this fashion, a player chooses his best strategy based on the choice of the others.

Adoption of the maximin strategy, according to Pindyck and Rubinfeld (2002, p.469), represents a player's option to maximize the minimum gain to be obtained. Gremaud and Braga (1998, p.254) summarize this strategy as follows: "I'm not sure what I'll do, but I'll choose the one that will be the 'least bad' of the worst possible results."

Besides these strategies, there are mixed strategies, in other words, those where the players carry out actions randomly from two or more possible choices, based on a set of probabilities.

Using game theory as a foundation, the disclosure process can be seen as a two-player (player 1: the firm and/or managers versus player 2: investors), non-cooperative and sequential game.

Works on association-based disclosure assume the disclosure process is exogenous and are concerned with evaluating the effects of the disclosure on changes in investors' actions. In this form, game theory can furnish models to assess the behavior of investors (player 2), since they make decisions based on the company's disclosure (action of player 1).

Studies of discretionary-based disclosure treat the disclosure process as endogenous and seek to examine the way managers and/or companies decide to reveal certain information. In this case, the game is analyzed from the viewpoint of player 1, i.e., the firm and/or managers assess their decision based on investors' actions.

Works on efficiency-based disclosure assume disclosure has not yet occurred and evaluate the types of disclosure that are most efficient, with investors' actions being endogenous. In this case, the game focuses on both players, because the objective is to assess the optimal solution for both.

The relationship of disclosure theory to game theory has been little explored. Nevertheless, some papers have used this association seeking to evaluate the disclosure process. Among these, we can cite Stochen (2000) and Korn and Schiller (2003). 


\section{FINAL CONSIDERATIONS AND SUGGESTIONS FOR FURTHER STUDY}

Studies of disclosure in the international scenario face several challenges, as discussed in this article. Since the 1980s, various works have been published aiming to shed light on the disclosure phenomenon.

The paper by Verrecchia (2001) supplies a broad theoretical basis to develop this line of research, classifying works into three categories: association-based, discretionary based and efficiency-based disclosure. For each category, the author presents mathematical relations that seek to represent the disclosure phenomenon and the variables related to it. Faced with this, there are a variety of possibilities to conduct empirical studies, using these analytical models to construct hypotheses, which in turn can be tested using real data.

To illustrate this potential for works, Verrecchia (2001, p. 173-175) suggests some directions for future research, such as studying the relation between disclosure and the reduction of informational asymmetry. According to him, this relation associates disclosure to efficiency, and in this way provides an economic motive for the utility of financial statements.

Besides this, the disclosure process can also be modeled assuming the conditions of a game, in which player 1 (firm and/or management) discloses (or not) certain information and player 2 (capital market investors) react to this action, seeking to maximize their wealth. In this way, the theory of disclosure can be remodeled on the structure developed by the theory of games. We suggest this is a particularly rich field for further investigation.

We hope this article has contributed to a better understanding of the theory of disclosure and will serve as motivation for other Brazilian researchers to prepare empirical works using this essay as a theoretical framework.

\section{REFERENCES}

DIAS FILHO, José Maria; MACHADO, Luiz Henrique Baptista. Abordagens de Pesquisa em Contabilidade. In: Sérgio de Iudícibus e Alexsandro Broedel Lopes (coordinators). Teoria Avançada da Contabilidade. São Paulo: Atlas, 2004.

DYE, Ronald A. An Evaluation of "Essays on Disclosure" and the Disclosure Literature in Accounting. Journal of Accounting and Economics, no. 32, pp. 181-135, 2001.

DYE, Ronald E. Disclosure of Nonproprietary Information. Journal of Accounting

Research, Vol. 23, no. 1, pp. 123-145, Spring 1985.

GREMAUD, Amaury Patrick; BRAGA, Márcio Bobik. Teoria dos Jogos: Uma Introdução. In: Diva Benevides Pinho and Marco Antonio Sandoval de Vasconcellos (organizers). Manual de Economia. 3rd ed. São Paulo: Saraiva, 1998.

KORN, Evelyn; SCHILLER, Ulf. Voluntary disclosure of nonproprietary information: a complete equilibrium characterization. Journal of Business Finance \& Accounting. Vol.30, no. 9 and 10, pp.1327-1339, Nov.-Dec. 2003.

MAS-COLELL, Andreu; WHINSTON, Michael D.; GREEN, Jerry R. Microeconomic

Theory. New York: Oxford University Press, 1995.

PINDYCK, Robert S.; RUBINFELD, Daniel L. Microeconomia. 5th ed. São Paulo: Prentice Hall, 2002.

STOCKEN, Phillip C. Credibility of voluntary disclosure. The Rand Journal of Economics. Vol.31, no.2, pp.359-374, Summer 2000.

VERRECCHIA, Robert E. Discretionary Disclosure. Journal of Accounting and

Economics, no. 5, pp. 179-194, 1983. 
VERRECCHIA, Robert E. Essays on Disclosure. Journal of Accounting and Economics, no. 32, pp. 97-180, 2001.

\footnotetext{
${ }^{\mathrm{i}}$ This citation is valid for the entire section.

${ }^{\text {ii }}$ For more information on these models, see Verrecchia (2001, pp. 106-139).

iii This citation is valid for the entire section.

iv See, for example, Verrecchia (1983).

v According to Dye (1985, p. 123), this refers to any information whose disclosure potentially alters the firm's future earnings.

${ }^{v i}$ Private costs refer to the costs incurred by disclosing proprietary information.

vii Another way to determine the maximum of the function $f(x)$ is to solve the equation $f^{\prime}(x)=0$, where $f^{\prime}(x)$ is the first derivative of $f(x)$.

viii This citation is valid for the entire section.

ix The mathematical development of this formula is described in Verrecchia (2001, pp. 168-169).
} 